\title{
Atomic layer deposition on porous powders with in situ gravimetric monitoring in a modular fixed bed reactor setup
}

Cite as: Rev. Sci. Instrum. 88, 074102 (2017); https://doi.org/10.1063/1.4992023

Submitted: 14 March 2017 . Accepted: 24 June 2017 . Published Online: 19 July 2017

V. E. Strempel, R. Naumann d'Alnoncourt (D), M. Driess, and F. Rosowski
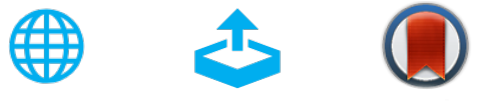

\section{ARTICLES YOU MAY BE INTERESTED IN}

Surface chemistry of atomic layer deposition: A case study for the trimethylaluminum/ water process

Journal of Applied Physics 97, 121301 (2005); https://doi.org/10.1063/1.1940727

Enhancing of catalytic properties of vanadia via surface doping with phosphorus using atomic layer deposition

Journal of Vacuum Science \& Technology A 34, 01 A135 (2016); https:// doi.org/10.1116/1.4936390

Review Article: Catalysts design and synthesis via selective atomic layer deposition Journal of Vacuum Science \& Technology A 36, 010801 (2018); https:// doi.org/10.1116/1.5000587

\section{Lock-in Amplifiers up to $600 \mathrm{MHz}$}
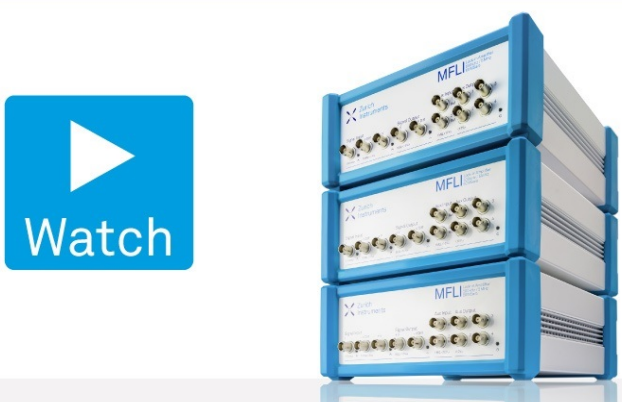


\title{
Atomic layer deposition on porous powders with in situ gravimetric monitoring in a modular fixed bed reactor setup
}

\author{
V. E. Strempel, ${ }^{1}{ }^{R}$. Naumann d'Alnoncourt, ${ }^{1, a)}$ M. Driess, ${ }^{1,2}$ and F. Rosowski ${ }^{1,3}$ \\ ${ }^{1}$ BasCat-UniCat BASF JointLab, Technische Universität Berlin, Hardenbergstraße 36, 10623 Berlin, Germany \\ ${ }^{2}$ Institut für Chemie, Technische Universität Berlin, Straße des 17. Juni 135, 10623 Berlin, Germany \\ ${ }^{3}$ Process Research and Chemical Engineering, BASF SE, Carl-Bosch-Straße 38, 67056 Ludwigshafen, Germany
}

(Received 14 March 2017; accepted 24 June 2017; published online 19 July 2017)

\begin{abstract}
A modular setup for Atomic Layer Deposition (ALD) on high-surface powder substrates in fixed bed reactors with a gravimetric in situ monitoring was developed. The design and operation are described in detail. An integrated magnetically suspended balance records mass changes during ALD. The highly versatile setup consists of three modular main units: a dosing unit, a reactor unit, and a downstream unit. The reactor unit includes the balance, a large fixed bed reactor, and a quartz crystal microbalance. The dosing unit is equipped with a complex manifold to deliver gases and gaseous reagents including three different ALD precursors, five oxidizing or reducing agents, and two purge gas lines. The system employs reactor temperatures and pressures in the range of $25-600{ }^{\circ} \mathrm{C}$ and $10^{-3}$ to 1 bar, respectively. Typically, powder batches between $100 \mathrm{mg}$ and $50 \mathrm{~g}$ can be coated. The capabilities of the setup are demonstrated by coating mesoporous $\mathrm{SiO}_{2}$ powder with a thin $\mathrm{AlO}_{\mathrm{x}}$ (submono) layer using three cycles with trimethylaluminium and $\mathrm{H}_{2} \mathrm{O}$. The self-limiting nature of the deposition has been verified with the in situ gravimetric monitoring and full saturation curves are presented. The process parameters were used for a scale-up in a large fixed bed reactor. The samples were analyzed with established analytics such as X-ray diffraction, $\mathrm{N}_{2}$ adsorption, transmission electron microscopy, and inductively coupled plasma optical emission spectrometry. Published by AIP Publishing. [http://dx.doi.org/10.1063/1.4992023]
\end{abstract}

\section{INTRODUCTION}

Recently, Atomic Layer Deposition (ALD) developed to a valuable, high-precision tool for the synthesis of heterogeneous catalysts. ${ }^{1,2}$ Few ALD cycles can lead to homogeneously distributed precursor deposits, which can act as active sites or promoters in catalysis., ${ }^{3,4}$ The selflimiting character of the reactions makes it possible to achieve uniformly distributed deposits and any number of monomolecular layers especially on porous highsurface-area solids, which are of particular interest for catalysis. ${ }^{5,6}$

Traditionally, ALD is a thin film deposition technique, which uses two vapor phase precursors. ${ }^{7,8}$ A substrate is sequentially exposed to an overdose of metal and non-metal precursors by applying sufficient inert gas purging in between. The precursor molecules react with surface sites (e.g., $\mathrm{OH}$ groups) until saturation. ${ }^{9}$ ALD is therefore always selflimiting, as the reaction terminates once all the reactive sites on the surface are consumed or sterically shielded. ${ }^{10}$ By repeating the overall cycle, the thickness of the grown film can be controlled by fractions of a nanometer. ${ }^{11}$ Usually, the first ALD cycles differ in mechanism and growth from the following cycles since they occur mostly on the surface of the original substrate. ${ }^{12,13}$

A universal reactor technique for the coating of powders/particles via ALD does not yet exist. ${ }^{14,15}$ In fact, the

\footnotetext{
a)Electronic mail: r.naumann@bascat.tu-berlin.de
}

reactor is designed based on the specific requirements of the individual challenge. The intricacy concerning the surface modification of powders is not only the large surface area of the substrate but also broad pore size distributions and other substrate characteristics, which often preclude the use of different reactor types. ${ }^{16}$ For instance, fluidized bed reactors are already widely used and offer excellent heat and mass transfer between the gas and solid phases. ${ }^{17,18}$ As an alternative to the fluidized bed reactor, particles can also be moved during the process in a low-speed rotating cartridge in the so-called rotary reactor. ${ }^{15,19}$ This design is more similar to basic ALD flowthrough/cross-flow reactors, ${ }^{20}$ where the precursor gas overflows the wafer surface, with the difference, that the surface is a moving powder filling. A conveniently plain reactor type for powder coating is a fixed bed. ${ }^{21,22}$ Here the powder is filled in a vertical tube reactor with gases flowing through the powder bed from top to bottom. Excellent contact of gas and solid, easy application and heating, and less restriction concerning particle size and shapes are compelling advantages of this reactor geometry. ${ }^{23,24}$

In situ studies of ALD processes provide fundamental insight into surface chemistry and recently got more attention. ${ }^{25-27}$ Unfortunately, some in situ analytics like spectroscopic ellipsometry ${ }^{28}$ can only be applied to flat substrates. The commonly used in situ analysis with a Quartz Crystal Microbalance (QCM) can solely give information about the growth thickness on the $\mathrm{SiO}_{2}$ crystal or on preliminary grown films on this crystal. ${ }^{29}$ As our main application of ALD is the synthesis of catalysts in the form of powder and in a sub-monolayer regime, a better 
understanding of the first cycles on powder substrates is of great importance.

Information on the process of ALD can be obtained by measuring the mass of the sample during reaction half cycles. Gravimetry is an effective and nondestructive way of studying ALD, particularly on high surface samples. For instance, Seki et al. studied the growth of flat substrates by suspending a small wafer from an electrobalance. ${ }^{30,31}$ Tolmachev et al. were the first to research on $\mathrm{TiO}_{2}$ layers synthesized via ALD on porous powders using a microbalance. ${ }^{32}$ However, both groups did not publish detailed gravimetric data. Here, we present for the first time full ALD mass gains and saturation curves measured in situ on powders in a fixed bed reactor.

Our ALD setup with integrated in situ gravimetric monitoring of the deposition via a thermal magnetic suspension balance (MSB) offers the possibility to analyze the deposition process in real time. The capabilities of the setup are demonstrated by coating porous $\mathrm{SiO}_{2}$ powder with a thin $\mathrm{AlO}_{\mathrm{x}}$ layer. The self-limiting nature of the deposition has been verified with the in situ gravimetric monitoring. By combining the gravimetric data with online mass spectrometry and further chemical and physical analysis of the samples $\left[\mathrm{N}_{2}\right.$ adsorption, $\mathrm{X}$-ray diffraction measurements (XRD), inductively coupled plasma optical emission spectrometry (ICP-OES), and high-resolution transmission electron microscopy (HRTEM)], we obtained new insights into the process of ALD growth on high-surface powder substrates.

\section{SETUP DESIGN}

The self-constructed ALD setup (Fig. 1) is designed for the deposition on powders in fixed bed reactors. It consists of three main units: the dosing unit (A), the reactor unit (B), and the downstream unit $(\mathrm{C})$. The reactor unit comprises the thermal balance used as a small fixed bed reactor (B.1), a large fixed bed reactor (B.2), and a quartz crystal microbalance (QCM) (B.3). Each part of the system as well as safety aspects is presented separately. The modular structure with a fixed dosing and downstream unit and an exchangeable reactor unit makes the system highly versatile and allows the coating of powder batches between $100 \mathrm{mg}$ and $50 \mathrm{~g}$.

The setup is equipped with a complex manifold that delivers gases and gaseous reagents, which include three different ALD precursors, five oxidizing or reducing agents, and two purge gas lines. Reactor temperatures and pressures in the range of $25-600{ }^{\circ} \mathrm{C}$ and $10^{-3}$ to $1 \mathrm{bar}$, respectively, can be applied. To prevent condensation, reactors and switching valves are placed into heating ovens (MMM Ecocell). Gas delivery lines, exhaust lines, and thermal bridges between ovens and reactors are actively heated. If not indicated differently, the assembly is made of $1 / 8$ in. stainless steel tubes, compression fittings, and bellow-type valves.

\section{A. Dosing unit}

The dosing unit provides the desired gas mixture with and without precursors for the reactor unit. The unit can be subdivided into four main gas lines: (1) one $\mathrm{N}_{2}$ line used

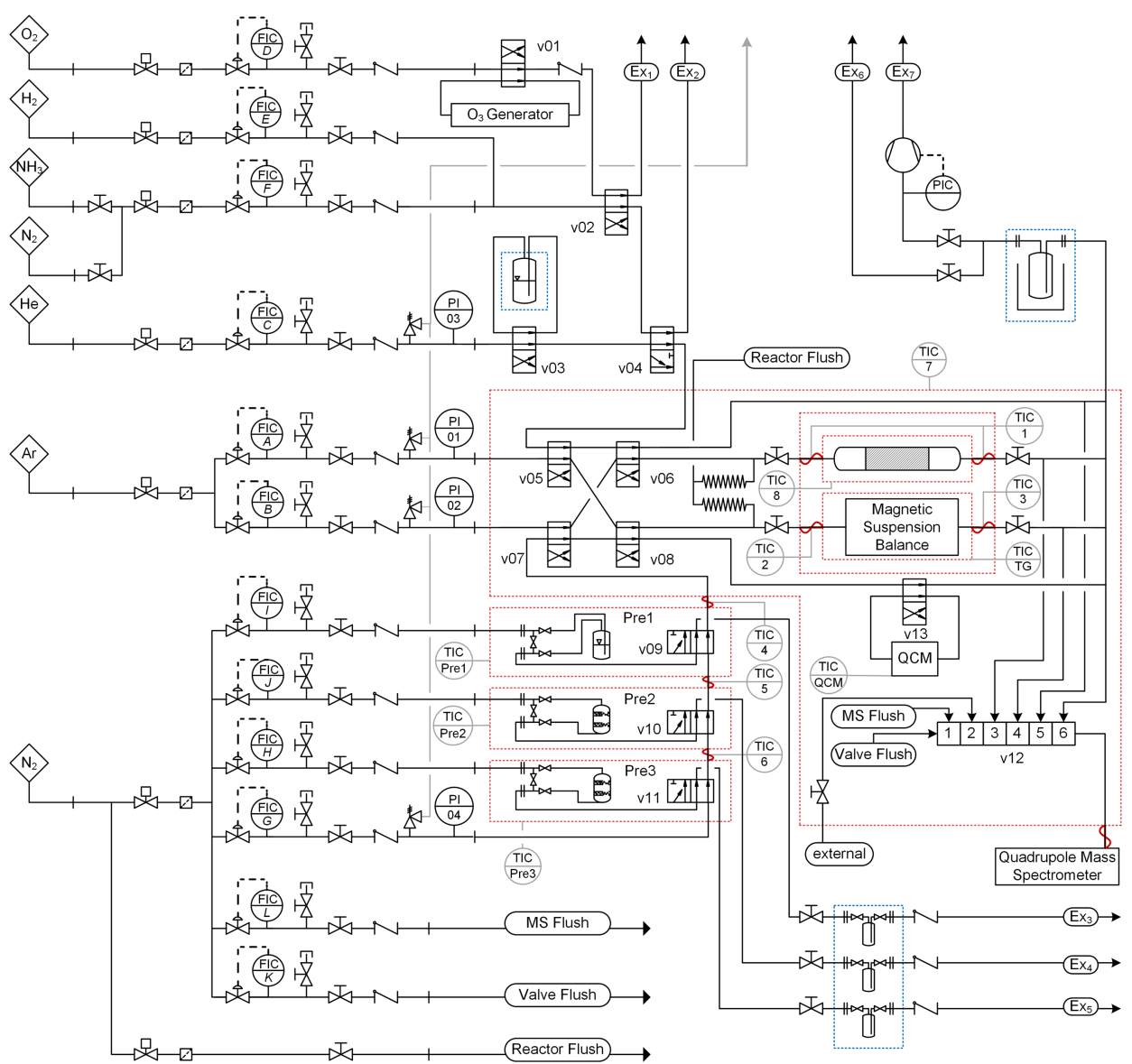

FIG. 1. Process flowsheet of ALD setup. The system is connected to 7 gas lines from the laboratory, which split into a complex manifold to provide the setup with the desired gas mixtures, including 3 different ALD precursors, 5 oxidizing or reducing agents, and 2 purge gas lines. The reactor unit is presented in the right middle part and includes the magnetic suspension balance, the large fixed bed reactor, and the quartz crystal microbalance. Reactor temperatures and pressures in the range of $25-600^{\circ} \mathrm{C}$ and $10^{-3}$ to 1 bar can be applied. Gas delivery lines, exhaust lines, and thermal bridges between ovens and reactors are actively heated. 
to carry and saturate solid and liquid precursors, (2) one $\mathrm{He}$ line interconnected to reactant gases $\left(\mathrm{O}_{2} / \mathrm{O}_{3}, \mathrm{H}_{2}\right.$, and $\left.\mathrm{NH}_{3}\right)$ and a $\mathrm{H}_{2} \mathrm{O}$ saturator, and (3) two Ar lines used for purging. An arrangement of four 4-port-2-way valves (valves v05-v08) before the reactor unit allows interchanging the main gases between the two following reactor lines and two bypass lines. All four lines unite in the downstream unit. The individual regulation panels for the gases include a pneumatic safety valve, a filter, a mass flow controller (MFC), a branch connection with diaphragm stop valve (for calibration, etc.), a diaphragm stop valve, and a check valve. The main gas lines also contain a pressure relief valve and a pressure gauge. Gas flows are accurately adjusted with Bronkhorst HI-TEC MFCs (EL-FLOW Select) and range for main gas lines $\left(\mathrm{Ar}, \mathrm{He}, \mathrm{N}_{2}\right.$ ) between 0 and $500 \mathrm{ml} \mathrm{min}^{-1}$ and for $\mathrm{O}_{2}, \mathrm{H}_{2}, \mathrm{NH}_{3}$, and three precursor $\mathrm{N}_{2}$ lines between 0 and $100 \mathrm{ml} \mathrm{min}^{-1}$.

The $\mathrm{N}_{2}$ line distributes in seven lines (Fig. 1): (1) one safety reactor flush line, (2) two flush lines for the Quadrupole Mass Spectrometer (QMS) connected with the multiport valve, (3) one main gas line, and (4) three gas lines for precursor saturators. The self-constructed saturator chambers consist of $1 / 2$ in. tubing with a distributor plate and feature a valve block in $1 / 4$ in. tubing for purging after reintegration into the setup. Reactive precursors $(1-100 \mathrm{ml})$ are typically funneled into the chambers in a glove box. The chambers are connected to the corresponding $\mathrm{N}_{2}$ line via two-Variable Compression Ratio (VCR) - type fittings. The precursor vapors from the different saturators can be diluted with the main $\mathrm{N}_{2}$ flow using special engraved valves (Vici Valco, 6-port-2-way). The dilution avoids condensation of the precursor vapor and allows its accurate dosage. If the precursor vapor is not fed into the main $\mathrm{N}_{2}$ stream, it flows to a separate cooling trap for precursor retrieval.

The He line carries the oxidizing and reducing agents to the reactor unit. The desired reaction mixture is regulated with four valves (valves v01-v04, see Fig. 1). $\mathrm{O}_{3}$ can be produced in a generator by dielectric-barrier discharge (Innotec OGVi-8G Lab), which is integrated in the $\mathrm{O}_{2}$ line and can be switched online if necessary. The $\mathrm{NH}_{3}$ line is equipped with an additional $\mathrm{N}_{2}$ purge line. The 4-port-2-way valve (v02) interchanging the $\mathrm{O}_{2} / \mathrm{O}_{3}$ line and the $\mathrm{H}_{2} / \mathrm{NH}_{3}$ line avoids an accidental production of dangerous and explosive gas mixtures. $\mathrm{O}_{2} / \mathrm{O}_{3}$ and $\mathrm{H}_{2} / \mathrm{NH}_{3}$ lines are then diluted with $\mathrm{He}$ (v04) via a custom engraved mixing valve (v04). $\mathrm{H}_{2} \mathrm{O}$ is supplied via a temperature-regulated saturator that can be switched online directly in the He line (v03).

\section{B. Reactor unit}

The reactor unit can be divided into three parts: (1) the balance, (2) the large fixed bed reactor, and (3) the QCM. All reactors are fed by the dosing manifold and the desired gases are distributed via an arrangement of four 4-port-2-way valves (Vici Valco EUDA-64UWE, valves v05-v08, see Fig. 1). The two Ar lines, the $\mathrm{N}_{2}$ precursor line, and the He reactant line can be interchanged between the three reactors and one bypass line.

The balance and the QCM play central roles in the development of a new ALD process. The typical sample volume in the balance is $1 \mathrm{ml}$. The large fixed bed reactor is used for scale-up, i.e., sample volumes above $3.5 \mathrm{ml}$. Routinely, the first experiments with a new substrate and/or precursor are conducted in the balance and/or the QCM to study and understand the ALD process. Self-termination of the processes can be verified and temperature and flow parameters can be optimized. Afterwards, the ALD parameters can be transferred to the large fixed bed reactor.

\section{Magnetic suspension balance}

The thermal gravimetric analysis system (TGA) is based on a Magnetic Suspension Balance (MSB) with a vertical geometry custom built by Rubotherm. The MSB separates the crucible chamber and the weighing unit and therefore allows introducing corrosive, toxic, and highly reactive gases (e.g., ALD precursors) without damaging the weighing system itself. Crucible and weighing system are magnetically coupled via a permanent magnet and an electromagnet, respectively. A schematic view of the measuring cell is given in Fig. 2.

The balance is a special version of the IsoSORP® system $^{33,34}$ and was developed to investigate mass transfer processes in a forced flow of gas through bulk material beds. In the forced flow through operation mode (FFT), the bulk material container is placed on a sealed plate and decoupled from the permanent magnet using a deposition cage. The gas is forced to flow through the material, which is stacked on the sieve-like bottom of the crucible (Fig. 2, left scheme). The FFT mode is a small fixed bed reactor to all intents and purposes. After user-defined time intervals, the container is lifted to a freely suspended state by the MSB and its weight is recorded (Fig. 2, right scheme) to detect distinct mass changes due to the mass transfer from or to the gas phase easily. The FFT option can be used in addition to the standard suspended operation mode. It is possible to switch the measuring cell from the standard operation to the FFT mode.
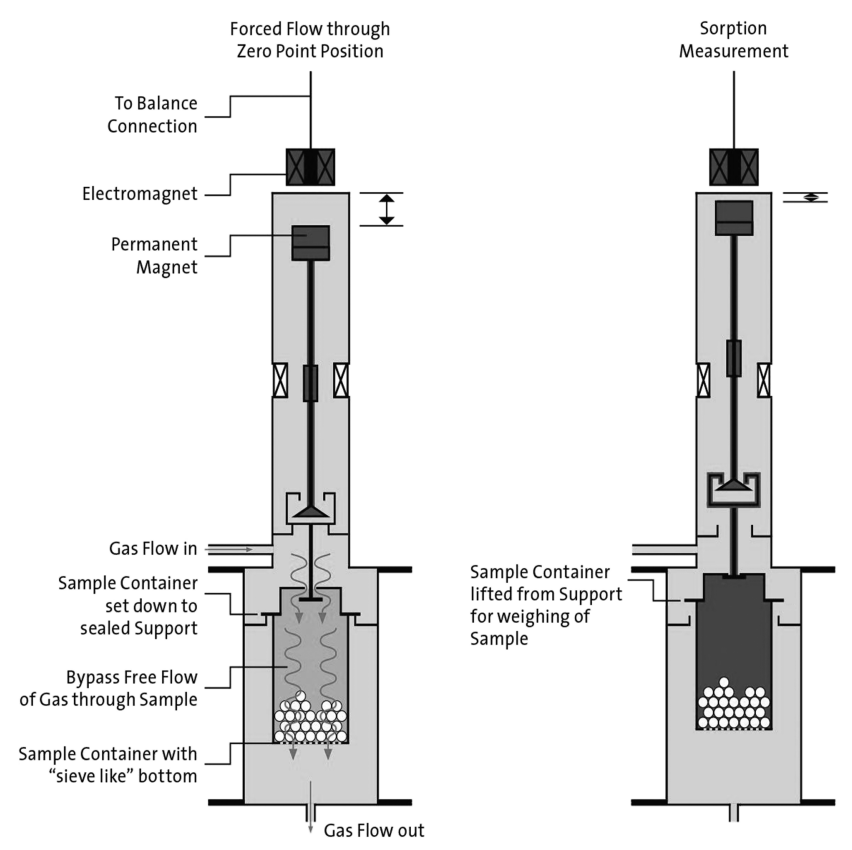

FIG. 2. Cross-sectional view of the magnetic suspension balance (MSB). Left: forced flow through mode. Right: sorption mode with a suspended crucible. Reprinted with permission from Rubotherm GMbH. Copyright 2017 Rubotherm $\mathrm{GmbH} .{ }^{40}$ 
Additionally, the MSB records and corrects baseline drifts and recalibrates itself during the measurements providing stability and accuracy especially for long term measurements. The resolution of $10 \mu \mathrm{g}$ with an uncertainty $<0.002 \%$ allows the precise monitoring of mass changes even on low surface area substrates. Operating conditions of this instrument are $0-200{ }^{\circ} \mathrm{C}$ for the coupling and $0-600{ }^{\circ} \mathrm{C}$ for the crucible in an UHV to 1 bar pressure regime. The system is free of coldspots. Samples and crucibles can be exchanged by opening the $40 \mathrm{~mm}$ flat sealed flange connection above the deposition cage. Usually gold coated copper gaskets are used to achieve a vacuum seal. The FFT crucible holds up to $3.5 \mathrm{ml}$ of sample material. The maximum load of the weighing system is $20 \mathrm{~g}$.

\section{Large fixed bed reactor}

Beside the MSB the setup features a large heating oven (Memmert UF260) for temperatures up to $300{ }^{\circ} \mathrm{C}$ that contains connections for differently sized fixed-bed reactors. For temperatures up to $600{ }^{\circ} \mathrm{C}$, a split tube furnace (HTM Reetz) is installed in the oven chamber, which can be opened along the longitudinal axis with an isothermal zone of $120 \mathrm{~mm}$. The inner diameter of the furnace is $20 \mathrm{~mm}$. Currently two types of materials for tube reactors are used: (1) stainless steel and (2) quartz. Many samples modified in the ALD setup are tested afterwards in their catalytic activity. Thus the fixed bed reactors are matched with the required dimensions for our catalytic testing facilities, and the entire reactor can be taken directly to the catalyst testing after the ALD process without transferring the sample. For instance, a typical stainless steel reactor used in a selective oxidation facility has a total length of $420 \mathrm{~mm}$ and an inner diameter between 7 and $10 \mathrm{~mm}$, which can be easily implemented in the ALD setup. Stainless steel reactors can be metal sealed, which is favored. On the other hand, possible color changes during the ALD can be visually monitored only in quartz reactors as the oven is equipped with a window. Furthermore quartz has hardly any reactive surface sites for ALD reactions and can therefore not be coated. Quartz reactors are connected via ultra-torr fittings with fluoroelastomer (FKM) O-rings. Currently, the maximum load for our reactors is dimension-limited to $50 \mathrm{ml}$. Still larger tube reactors can be implemented if necessary.

\section{Quartz crystal microbalance}

In addition to the in situ thermal balance and the large fixed bed reactor, a Quartz Crystal Microbalance (QCM) is integrated in the setup. We use a Colnatec Tempe ${ }^{\mathrm{TM}}$ Sensor in combination with an Eon ${ }^{\mathrm{TM}}$ film thickness controller and $14 \mathrm{~mm} \mathrm{RCTM}$ quartz crystals with Inficon contact geometry. The sensor features a head with an integrated and independent solid state heater $\left(500{ }^{\circ} \mathrm{C} \max \right)$ and crystal rejuvenation technology. The whole sensor is mounted on a CF40 vacuum flange, which is connected to a 5 in. long stainless steel tube serving as the reaction chamber for the crystal. With a 4-port2-way valve, the microbalance can be switched to the process. We have chosen to install the QCM directly in one of the four gas lines, parallel to the other two reactors. In general, the QCM is useful to verify reactive precursors in the gas flow and helps determine the correct coating temperatures for new precursors. However, the coating parameters for a quartz crystal cannot certainly be transferred to coatings of high surface substrate of different composition, but they help understand the precursor chemistry and are a convenient starting point for the process development for powder substrates. Suitable parameters are determined in the MSB and can finally be transferred to the fixed bed reactor.

\section{Downstream unit}

The third main part of the setup is the downstream unit, which contains the QMS system. After the reactor unit, all gas lines unite in a single downstream line with an enlarged diameter of $1 / 2 \mathrm{in}$. Chemical residues and byproducts are removed by two cooling traps. The cooling traps (solid $\mathrm{CO}_{2}$ in 2-propanol at $-78{ }^{\circ} \mathrm{C}$ ) freeze out unreacted precursors and byproducts. After each ALD experiment, the residues in the traps need further treatment with a suitable scavenger, e.g., $\mathrm{H}_{2} \mathrm{O}$.

Monitoring of volatile species is performed with a QMS system (Pfeiffer PrismaPlus QMA 220) with a gastight ion source and a heated segregation-free capillary gas inlet. The QMS measures a mass to charge ratio up to 300 , which is necessary for the detection of large precursor molecules and fragments. As the QMS is an inherent part of the setup that operates in a pressure regime of $10^{-3}-1$ bar, the spectrometer features a special regulation to adjust to the necessary inlet pressure. This is achieved by a combination of two valves: (1) a special dosing valve for the regulation of the antechamber vacuum and (2) an inlet valve right before the orifice of the main chamber. By using different inert carrier gases for the three different ALD cycle segments (precursor, reactant gas, and purging), the QMS allows us to accurately determine segment lengths. The QMS capillary is directly connected with a 6-port common outlet flow path selector valve (Vici Valco EUTA-6SC6MWE; valve v12 in Fig. 1), so the QMS can be switched between different observation spots in the setup. The selector valve selects one of the 6 streams. The selected stream flows from the outlet to the QMS. The non-selected streams converge to a common outlet. We use the common outlet as inlet for a MFC regulated $\mathrm{N}_{2}$ line. On that account, we constantly purge all non-selected lines and avoid condensation or reaction in those parts. The six different ports are connected to (1) the exhaust line of the thermal balance (port 3), (2) the exhaust line of the fixed bed reactor (port 4), (3) the QCM line (port 5), (4) the bypass line (port 6), (5) a bellow-type valve for the possible connection of an external device (port 2), and (6) an additional MFC regulated $\mathrm{N}_{2}$ line for QMS purging (port 1). The multiport valve offers a highly flexible utilization of the QMS, e.g., it can analyze precursor vapors in the setup that were not yet introduced into the reactor and are still in the bypass line.

Moreover the downstream unit contains the pumping system for pressures below atmosphere. Vacuum is maintained by a frequency regulated membrane pump (Vacuubrand MV 2 NT vario) with a minimal pressure of 0.3 mbar absolute according to specification. Two valves before the pump are used to bypass the pump, if the experiment is conducted under atmospheric pressure. 


\section{Safety}

Main safety issues concerning the setup are heating failures, clogging followed by a pressure increase, and unintentional release of hazardous chemicals. Chemicals used as ALD precursors might be highly flammable, explosive, toxic, or dangerous to the environment. Due to several safety precautions, the risks and consequences of failure have been largely minimized.

The entire setup is built in a cabinet made of aluminum profiles and acrylic glass panes, which is ventilated via two connections to the laboratory off gas system. The cabinet protects the environment and user in case of failure. Additionally, all components of the setup are connected to an interlock unit (IU), which is linked to several detectors: (1) a smoke and fire detector, (2) a flow sensor in the exhaust line, and (3) two detectors for burnable gases. One is installed directly in the cabinet and one is monitoring the atmosphere in the ovens. Two emergency shut down buttons are located at easily accessible positions.

In general, leakage is reduced by using metal gaskets and compression fittings. Heating failures are avoided as heating tapes are limited to $250{ }^{\circ} \mathrm{C}$ maximum temperature and are protected with a solidly grounded braiding. In the case of pressure build-ups over 1 bar overpressure, pressure release valves in the four main gas lines actuate.

\section{EXPERIMENTAL SECTION}

The ALD of $\mathrm{AlO}_{\mathrm{x}}$ on $\mathrm{SiO}_{2}$ powder was chosen as a probe reaction to validate the setup. We have chosen an amorphous and mesoporous $\mathrm{SiO}_{2}$ powder (Davisil) as our starting material. It is an unordered silica with a relatively broad pore size distribution compared to other ordered structures like SBA-15 or KIT-6. Consequently some analytics, like electron microscopy, can be challenging. However it features a very high surface area and can be purchased in large amounts at high purity with varied mesh sizes and average pore diameters. Therefore it is a well-known and widely used support material in particular for heterogeneous catalysts and also of high interest for our research and our industry partners. Trimethylaluminium (TMA) served as a precursor and $\mathrm{H}_{2} \mathrm{O}$ as the reactant. The correct ALD parameters and the selflimiting nature of the reactions were determined in the thermal balance. A scale-up was carried out in a large fixed bed reactor.

\section{A. Chemicals}

Silica powder $\left[\mathrm{SiO}_{2}\right.$, high-purity grade $\geq 99 \%$ (Davisil Grade 636), average pore size $60 \AA$, 35-60 mesh particle size, Sigma-Aldrich, specific surface area $506 \mathrm{~m}^{2} \mathrm{~g}^{-1}$ ] was used as a substrate. Trimethylaluminium $\left[\mathrm{Al}\left(\mathrm{CH}_{3}\right)_{3}\right.$, TMA, elec. gr., 99.999\% Al] and water $\left(\mathrm{H}_{2} \mathrm{O}, \mathrm{CHROMA-}\right.$ SOLV®, for HPLC, Riedel-de Haën) served as precursors and were used without further purification. High purity $\mathrm{N}_{2}$, $\mathrm{Ar}$, and $\mathrm{He}(99.999 \%)$ were used as carrier and purging gases.

\section{B. $A I O_{x} A L D$ experimental}

$\mathrm{AlO}_{\mathrm{x}}$ coating experiments were conducted at a reactor temperature of $200^{\circ} \mathrm{C}$ and with 3 complete cycles in the MSB and in a scale-up.

Before filling the $\mathrm{SiO}_{2}$ substrate into the special crucible for FFT operations in the balance, the sieve-like bottom of the crucible was slightly obturated with a thin layer of quartz wool to keep the sample material inside the crucible. A sample amount of $200 \mathrm{mg}$ was used, giving a surface area of approximately $100 \mathrm{~m}^{2}$ in the sample container. The reaction was carried out under a continuous total gas flow of $50 \mathrm{ml} \mathrm{min} \mathrm{m}^{-1}$ at atmospheric pressure. Moreover the entire setup was under constant gas flow of at least $10 \mathrm{ml} \mathrm{min}^{-1}$ in each gas line to exclude water and oxygen from atmosphere. The TMA saturator was heated to $25{ }^{\circ} \mathrm{C} . \mathrm{H}_{2} \mathrm{O}$ was kept in a saturator at $16{ }^{\circ} \mathrm{C}$. The heating components were adjusted to maintain an increasing temperature gradient from the precursor chamber to the reactor.

The thermal balance was in advance calibrated and tared under $10 \mathrm{ml} \mathrm{min}^{-1}$ Ar flow. The crucible was kept at FFT mode for $25 \mathrm{~min}$ and afterwards measured for $5 \mathrm{~min}$. Baseline drifts and recalibration were automatically done by the balance. The experiment started with heating up to $200{ }^{\circ} \mathrm{C}$ in $50 \mathrm{ml} \mathrm{min} \mathrm{m}^{-1}$ Ar. As soon as the balance gave a stable signal for $2 \mathrm{~h}$ and the setup was sufficiently heated, TMA was introduced. The liquid precursor was saturated in a constant gas flow of $25 \mathrm{ml} \mathrm{min} \mathrm{m}^{-1}$

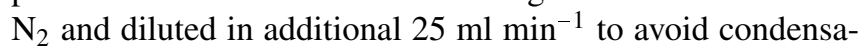
tion. A rough estimation of the TMA concentration in the gas feed based on the partial pressure of TMA at $25^{\circ} \mathrm{C}(4 \mathrm{mbar}$ as given by the MSDS) leads to a molar fraction of $0.2 \%$ of TMA in $\mathrm{N}_{2}$. Atmosphere changes in the reactor were monitored by online QMS during the experiment. We used a QMS filament of yttriated iridium $\left(\mathrm{Y}_{2} \mathrm{O}_{3} / \mathrm{Ir}\right)$ and the following settings: ion reference $105.0 \mathrm{~V}$, focus $-3.00 \mathrm{~V}$, field axis $-13.00 \mathrm{~V}$, and extraction $-75.00 \mathrm{~V}$. Precursor dosing was stopped when the balance reached equilibrium. After Ar purging, the procedure was repeated for the $\mathrm{H}_{2} \mathrm{O}$ half cycle. $\mathrm{H}_{2} \mathrm{O}$ was saturated in $50 \mathrm{ml} \mathrm{min}^{-1} \mathrm{He}$.

The scale-up experiment was conducted at $200{ }^{\circ} \mathrm{C}$ in a $1 / 4$ in. quartz tube. The ALD parameters and settings were transferred from the experiments in the balance. As the in situ gravimetric analysis is not possible in the large fixed bed reactor, the breakthrough curves of the unreacted precursor in the QMS were used to define the correct cycle times.

\section{Results and discussion}

We successfully conducted experiments with TMA and $\mathrm{H}_{2} \mathrm{O}$ at $200{ }^{\circ} \mathrm{C}$ leading to a thin $\mathrm{AlO}_{\mathrm{x}}$ deposit. Usually ALD is used to produce layers in the range of several $\mathrm{nm}$ with 50 and more cycles. ${ }^{7}$ As the focus of our work is the synthesis of sub-monolayer via $\mathrm{ALD},{ }^{4}$ the cycle amount conducted in this study is three. Sample \#0767 was synthesized in the MSB with the mass gain measured in situ. Sample \#1223 was synthesized in the large fixed bed reactor.

The reference $\mathrm{SiO}_{2}$ (\#0317) was analyzed with Thermogravimetric Analysis-Mass Spectrometry (TG-MS) to determine surface species in the untreated sample. The TG-MS 


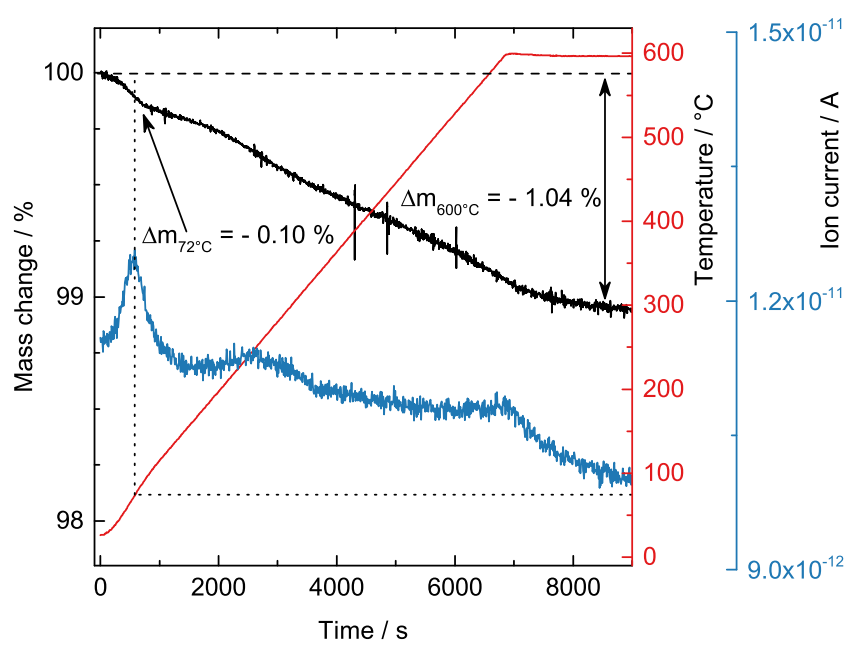

FIG. 3. TG-MS analysis of the $\mathrm{SiO}_{2}$ reference (\#0317). Shown are the relative mass change (black, left axis), the temperature (red, right axis), and ion current for $\mathrm{m} / \mathrm{z}=18$ (blue, additional axis right). Please note that the continuously open gas inlet of the mass spectrometer leads to a notable and with time drifting background signal for water.

data were acquired using a Netzsch-STA 449C thermoanalyzer equipped with an electromagnetic microbalance with top loading. The samples are evacuated and the sample chamber is re-filled with $5 \% \mathrm{O}_{2}$ in $\mathrm{Ar}$, which is maintained at a total flow rate of $100 \mathrm{ml} / \mathrm{min}$. A heating rate of $5 \mathrm{~K} / \mathrm{min}$ is used. The gas phase products are monitored with a quadrupole mass spectrometer (QMS200 ThermoStar, Balzers) coupled to the balance via a quartz capillary heated to $313 \mathrm{~K}$. The percentage mass change and temperature over time are shown in Fig. 3. In addition, the mass trace for $\mathrm{m} / \mathrm{z}=18$ is displayed, which is attributed to physisorbed $\mathrm{H}_{2} \mathrm{O}$ desorbing at $72{ }^{\circ} \mathrm{C}$. This trace gives the only relevant feature in the QMS data. We consequently decided to work with substrate temperatures of $200{ }^{\circ} \mathrm{C}$ to exclude effects induced by physisorbed water, but still have the major part of surface hydroxyl groups present.

The relative mass gain over time diagram during the deposition process itself is shown in Fig. 4 for the balance sample (\#0797). The dosing procedure is pictured in the upper part for clarification. A distinct saturation of mass gain by precursor interactions was observed for all half cycles and verifies a selfterminating surface reaction. Naturally, different carrier/purge gases lead to different buoyancy forces in the reactor, which is particularly notable when changing back to Ar after saturation is reached. However, as we compare the total mass changes only during Ar flow, buoyancy effects can be left out of consideration. (Note: the cycles are not equidistant because the valve switching was done manually.) The observed cycle times are much longer than for common wafer coatings with ALD. The used $\mathrm{SiO}_{2}$ has a calculated surface area of $506 \mathrm{~m}^{2} \mathrm{~g}^{-1}$, resulting in more than $100 \mathrm{~m}^{2}$ of surface in the crucible, which is four orders of magnitude larger than typical surface areas for wafers. The accordingly large amount of required precursors leads to long cycle times.

Beside the saturation curves, the in situ gravimetry gives the following information: (1) the total mass gain, which is around $12 \%-13 \%$ for each cycle and (2) the uptake distributes differently between the two half cycles for each cycle. In the first cycle, the $\mathrm{H}_{2} \mathrm{O}$ half cycle leads to a slight mass loss of $-0.7 \%$ possibly induced by condensation of emerging $\mathrm{OH}$ groups on the new surface. With increasing cycle number, the contribution of the $\mathrm{H}_{2} \mathrm{O}$ half cycle to the total mass gain increases from $0.4 \%$ for cycle 2 and $1.2 \%$ for cycle 3 . This indicates a change in the surface reactions between the precursors and the substrate. In general, the change of the surface reactions with cycle number is thoroughly anticipated, as the surface composition changes during the first ALD cycles from a $\mathrm{SiO}_{2}$ to an $\mathrm{AlO}_{\mathrm{x}}$ surface. A repetitive cycle with equal mass gains/Al gains will begin as soon as a complete $\mathrm{AlO}_{\mathrm{x}}$ layer is formed. $^{12}$

To compare our results with other ALD studies, it is necessary to determine the average growth per cycle, which is easily accessible in the case of flat substrates. A simple estimation of the thickness of the deposited layer based on the specific surface area of the substrate, the amount of deposited mass, and the assumption of a homogeneous layer of $\mathrm{Al}_{2} \mathrm{O}_{3}$ with a density of $3 \mathrm{~g} \mathrm{~cm}^{-3}$ at $200{ }^{\circ} \mathrm{C}$ yields a value of $0.81 \AA /$ cycle. This value is in good agreement with literature data. ${ }^{12,35}$

Supplementary to the gravimetric measurements, the QMS monitored the gas composition at the outlet of the balance to give information about precursor behavior and byproduct formation. Results for the first cycle are given in Fig. 5, as an example. Shown are the mass traces attributed to inert gases and precursors: 4 for $\mathrm{He}, 28$ for $\mathrm{N}_{2}, 40$ for Ar, 16 for $\mathrm{CH}_{4}$ (byproduct), 18 for $\mathrm{H}_{2} \mathrm{O}$ (reactant), and 57 for TMA

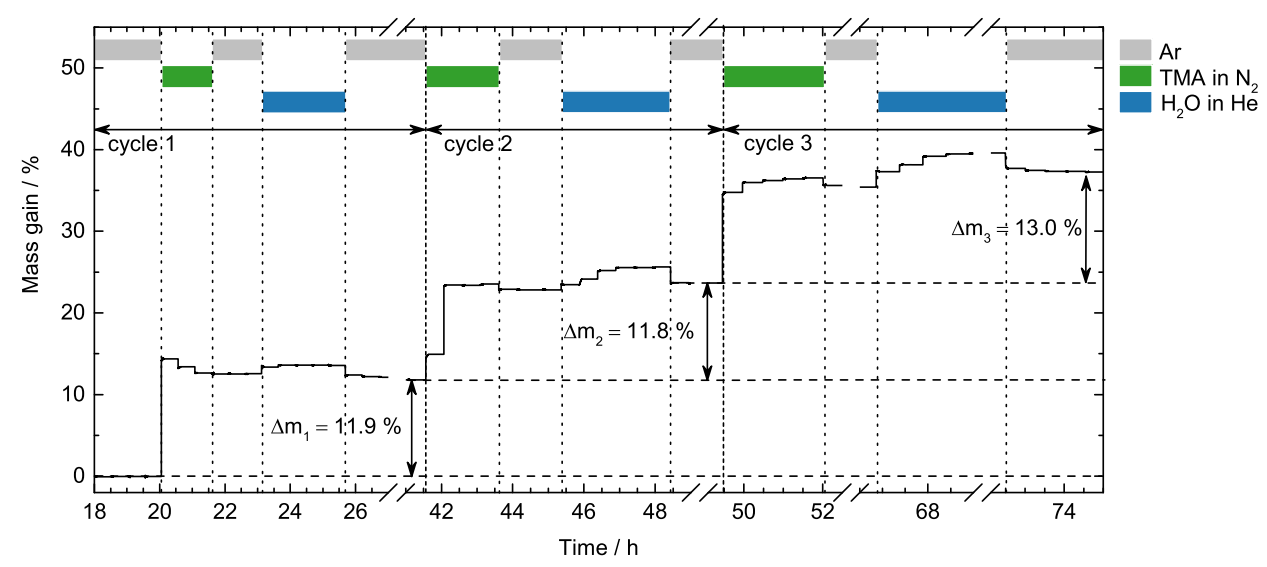

FIG. 4. Gravimetric in situ monitoring for sample \#0797: $\mathrm{AlO}_{\mathrm{x}} \mathrm{ALD}$ on $\mathrm{SiO}_{2}$ powder at $200{ }^{\circ} \mathrm{C}$ using TMA and $\mathrm{H}_{2} \mathrm{O}$. Shown is the percentage mass gain over time for three full ALD cycles. The dosing procedure is pictured in the upper part. 


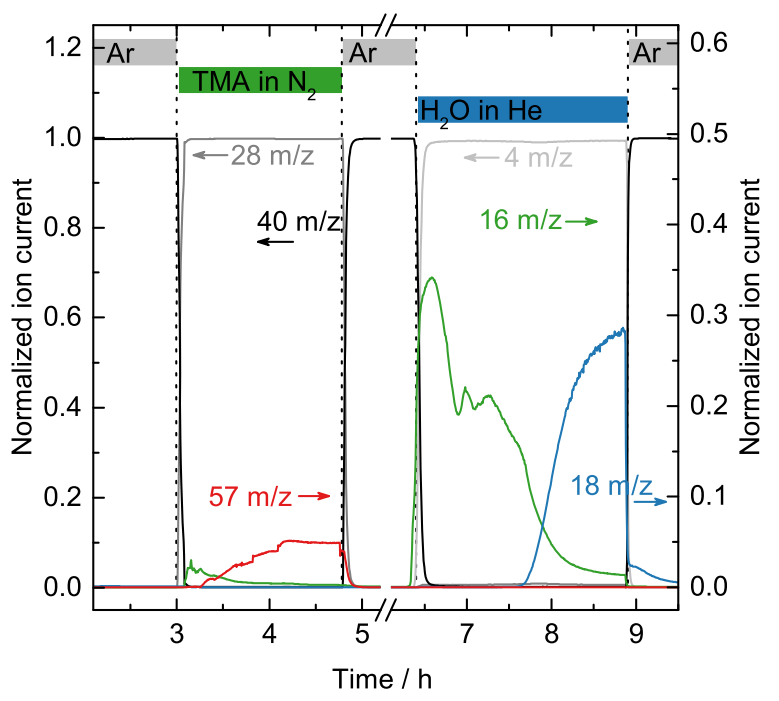

FIG. 5. Mass spectrometric monitoring for the first ALD cycle from sample \#0797: $\mathrm{AlO}_{\mathrm{x}} \mathrm{ALD}$ on $\mathrm{SiO}_{2}$ powder at $200^{\circ} \mathrm{C}$ using TMA and $\mathrm{H}_{2} \mathrm{O}$. Normalized ion currents over time for the following mass to charge ratios: 40 (Ar, black, left axis), 28 ( $\mathrm{N}_{2}$, dark grey, left axis), 4 (He, light grey, left axis), 16 $\left(\mathrm{CH}_{4}\right.$, green, right axis), 57 (TMA, red, right axis), and $18\left(\mathrm{H}_{2} \mathrm{O}\right.$, blue, right axis). Please note that water also has a minor contribution to the signal for $\mathrm{m} / \mathrm{z}=16$. The dosing procedure is pictured in the upper part.

(precursor). The change of the carrier gas between half cyclepurge-half cycle-purge is distinct and visible. $\mathrm{CH}_{4}$ is rapidly formed as soon as the precursor is introduced in the reactor. The $\mathrm{CH}_{4}$ signal drops and vanishes, when the unreacted precursors break through indicating a chromatographic reaction process in the fixed bed. The little inconsistencies of the breakthrough curves are due to the $5 \mathrm{~min}$ measuring interruption in the balance, when the sample container is lifted up and the precursor can bypass the container. Here, the presented curves are not further normalized to the chamber pressure and can therefore not be compared quantitatively.

High Resolution Transmission Electron Microscopy (HRTEM) images were recorded at a $\mathrm{c}_{\mathrm{s}}$-corrected TITAN 80300 Berlin Holography Special TEM, operated at $300 \mathrm{kV}$ to analyze the microstructure of the samples. Figure 6 shows an exemplary image of the coated $\mathrm{SiO}_{2}$ particles from the MSB experiment after 3 cycles. The sample features primary particles of around $5 \mathrm{~nm}$ with corresponding inner particle voids, responsible for the porosity of the material. As expected, we cannot observe $\mathrm{AlO}_{\mathrm{x}}$ layers or small clusters on the surface of the support with HRTEM. The contrast between the elements $\mathrm{Al}$ and $\mathrm{Si}$ is too low for better imaging, due to their close ordinal numbers and the small amount of Al. However we can exclude critical morphology changes of $\mathrm{SiO}_{2}$ during the ALD by comparing to TEM images in the literature, since amorphous $\mathrm{SiO}_{2}$ (Davisil 636) is a widely used support material. ${ }^{36,37}$ Furthermore we exclude large areas of $\mathrm{AlO}_{\mathrm{x}}$ islands, which additionally confirms a thoroughly dispersed $\mathrm{Al}$ species on the surface.

For the ALD process in the large fixed bed reactor without gravimetric analysis (sample \#1223), QMS analysis confirmed the changing gas atmosphere and breakthrough curves for all cycles (see Fig. 7). Compared to the MSB (Fig. 5), the breakthrough curves are sharper in the fixed bed reactor. This is due to the interruption of the FFT mode during gravimetric

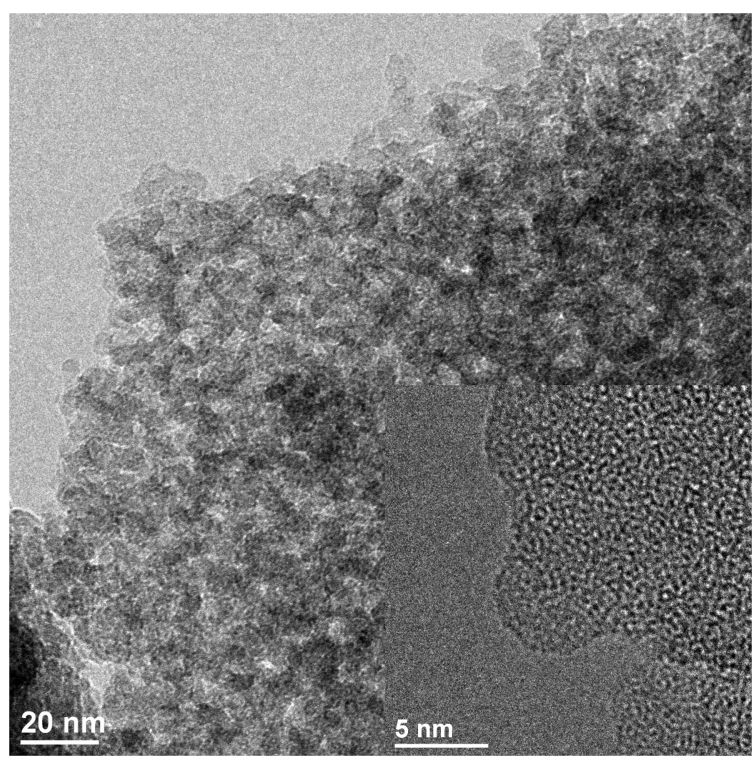

FIG. 6. HRTEM images of $\mathrm{SiO}_{2}$ after 3 ALD cycles with TMA and $\mathrm{H}_{2} \mathrm{O}$ at $200{ }^{\circ} \mathrm{C}$.

analysis and the dead volume of the balance after the crucible suspension, which needs to be purged. The fixed bed reactor does not hold any dead volume. The sample amount used for the scale-up is $10 \times$ higher than for the MSB experiment. For reliable statements concerning the homogeneity of the deposit in the entire fixed bed, we took one sample from the top of the filling, one from the middle, and one from the bottom and analyzed them separately. In the following, we give the resulting average and the standard deviation.

The specific surface area was calculated for all samples according to the multipoint Brunauer-Emmett-Teller method $(B E T)^{38}$ from liquid $\mathrm{N}_{2}$ adsorption and desorption isotherms measured on a Quantachrome Autosorb-6B analyzer. Prior to

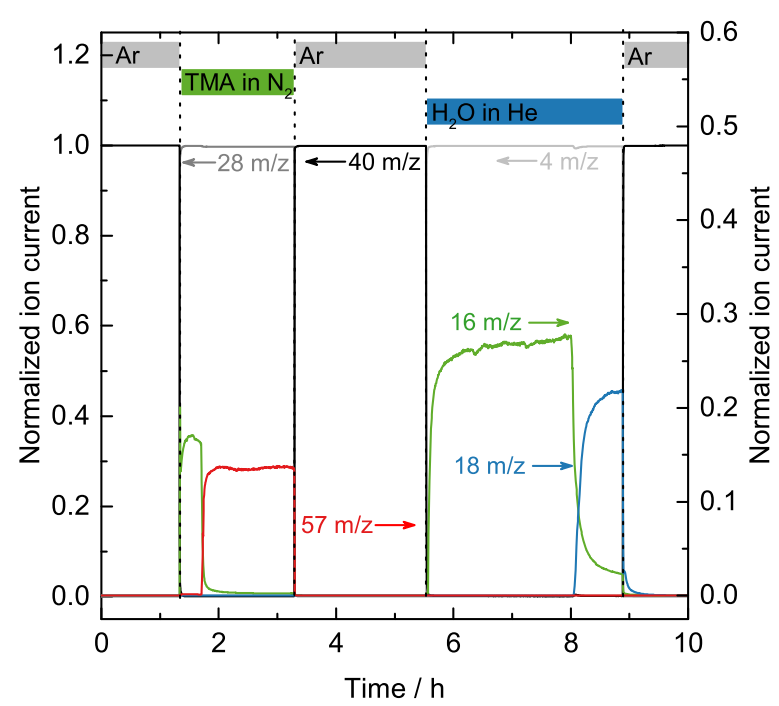

FIG. 7. Mass spectrometric monitoring for the first ALD cycle from sample \#1223 in the scale-up: $\mathrm{AlO}_{\mathrm{x}} \mathrm{ALD}$ on $\mathrm{SiO}_{2}$ powder at $200{ }^{\circ} \mathrm{C}$ using TMA and $\mathrm{H}_{2} \mathrm{O}$. Normalized ion currents as a function of time for the following mass to charge ratios: 40 (Ar, black, left axis), 28 ( $\mathrm{N}_{2}$, dark grey, left axis), 4 (He, light grey, left axis), $16\left(\mathrm{CH}_{4}\right.$, green, right axis), 57 (TMA, red, right axis), and 18 $\left(\mathrm{H}_{2} \mathrm{O}\right.$, blue, right axis). Please note that water has also a minor contribution to the signal for $\mathrm{m} / \mathrm{z}=16$. The dosing procedure is pictured in the upper part. 


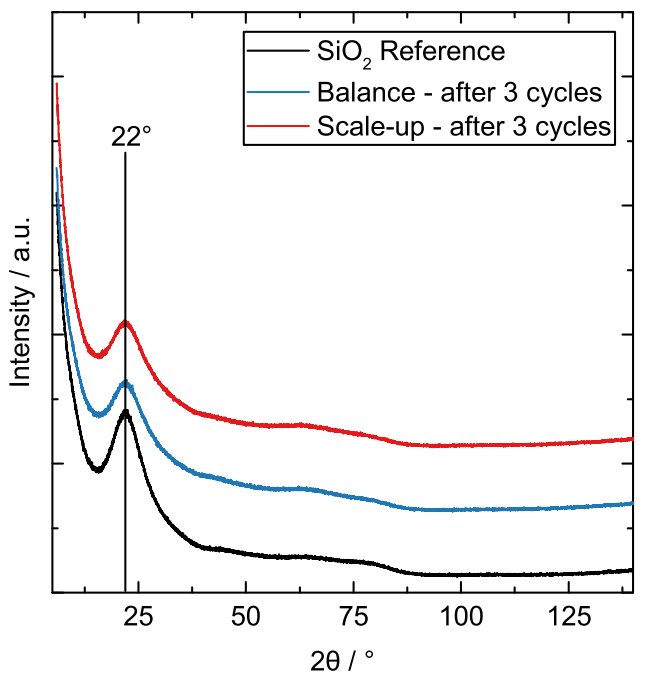

FIG. 8. XRD pattern of the reference $\mathrm{SiO}_{2}$ and the $\mathrm{AlO}_{\mathrm{x}}$ coated samples after 3 cycles.

the measurement, the samples were degassed in dynamic vacuum at $150{ }^{\circ} \mathrm{C}$ for $2 \mathrm{~h}$. As expected, the large surface area of $506 \mathrm{~m}^{2} \mathrm{~g}^{-1}$ for the reference $\mathrm{SiO}_{2}$ decreased during 3 ALD cycles to $337 \mathrm{~m}^{2} \mathrm{~g}^{-1}$ for the balance sample (\#0797) and to 309 $\pm 3.5 \mathrm{~m}^{2} \mathrm{~g}^{-1}$ for the scale-up sample (\#1223). In addition, quantitative analysis was performed by Inductively Coupled Plasma Optical Emission Spectroscopy (ICPOES, Varian 720-ES) to determine the Al content of the samples. Solutions from the powders were prepared via microwave assisted acid digestion at $300{ }^{\circ} \mathrm{C}$ to dissolve the deposited $\mathrm{AlO}_{\mathrm{x}}$. The determined $\mathrm{Al}$ contents were comparable for the balance sample with $16.7 \mathrm{wt} \% \mathrm{Al}$ and the scale-up sample with $16.5 \pm 0.9$ wt. $\%$ confirming the fixed bed reactor as a suitable reactor concept for ALD.

Powder X-ray diffraction (XRD) measurements were performed in Bragg-Brentano geometry on a Bruker AXS D8 Advance II theta/theta diffractometer, using Ni filtered $\mathrm{Cu} \mathrm{K} \alpha$ radiation and a position sensitive energy dispersive LynxEye silicon strip detector. Results are given in Fig. 8 and show that the $\mathrm{SiO}_{2}$ powder and the as-deposited $\mathrm{AlO}_{\mathrm{x}}$ coatings were amorphous in both reactors. One broad reflex at $22^{\circ}$ is attributed to amorphous $\mathrm{SiO}_{2} \cdot{ }^{36}$ No crystalline ad phases or phase changes are found.

A more detailed analysis of the ALD process itself, the influence of cycle number and substrate temperature, is given elsewhere. ${ }^{39}$

\section{SUMMARY AND CONCLUSIONS}

In this paper, we have described the design and operation of a complete, stand-alone modular ALD setup. We use fixed bed reactors for the coating of powders and particles. An integrated magnetically suspended thermal balance records in situ saturation curves. These data in combination with the online QMS analysis of the resulting gas phase can help gain new insights into the actual ALD process. Coating experiments of an amorphous mesoporous $\mathrm{SiO}_{2}$ with 3 cycles of TMA and
$\mathrm{H}_{2} \mathrm{O}$ to give an $\mathrm{AlO}_{\mathrm{x}}$ deposit were used to demonstrate the setup's utility. Recorded in situ mass gains and analysis of the $\mathrm{Al}$ wt. \% are in good agreement with the current literature. The calculated growth is $0.81 \AA$ per cycle at $200{ }^{\circ} \mathrm{C}$. The determined parameters for ALD were used for a scale-up in a large fixed bed reactor with a $10 \times$ higher substrate loading. Here the entire substrate bed was homogenously coated with $\mathrm{AlO}_{\mathrm{x}}$ in three cycles confirming the fixed bed reactor as a suitable reactor geometry for ALD experiments on porous particles.

\section{ACKNOWLEDGMENTS}

The authors want to thank the following co-workers: Stephen Lohr, Maike Hashagen, Jasmin Allan, and Frank Girgsdies from the Fritz-Haber-Institut der Max-PlanckGesellschaft and Jan Meißner, Benjamin Paul, and Kornelia Weh from the TU Berlin for their help and analytic measurements. Furthermore the authors want to acknowledge Roie Yerushalmi, Nicola Pinna, Daniel Löffler, Christoph Hoßbach, Saskia Buller, Marina Prenzel, and Kristina Pitzschel for their contribution.

The work was conducted in the framework of the BasCat JointLab between the BASF SE, the TU Berlin, and the FHI. We thank the Berlin Cluster of Excellence UniCat for their support.

${ }^{1}$ P. C. Stair, Top. Catal. 55, 93 (2012).

${ }^{2}$ B. J. O'Neill, D. H. K. Jackson, J. Lee, C. Canlas, P. C. Stair, C. L. Marshall, J. W. Elam, T. F. Kuech, J. A. Dumesic, and G. W. Huber, ACS Catal. 5, 1804 (2015)

${ }^{3}$ K. Cao, Q. Zhu, B. Shan, and R. Chen, Sci. Rep. 5, 8470 (2015).

${ }^{4}$ V. E. Strempel, D. Löffler, J. Kröhnert, K. Skorupska, B. Johnson, R. Naumann d'Alnoncourt, M. Driess, and F. Rosowski, J. Vac. Sci. Technol., A 34, 01 A135 (2016).

${ }^{5}$ C. Detavernier, J. Dendooven, S. P. Sree, K. F. Ludwig, and J. A. Martens, Chem. Soc. Rev. 40, 5242 (2011).

${ }^{6}$ M. Knez, K. Nielsch, and L. Niinistö, Adv. Mater. 19, 3425 (2007).

${ }^{7}$ S. M. George, Chem. Rev. 110, 111 (2010).

${ }^{8}$ V. Miikkulainen, M. Leskelä, M. Ritala, and R. L. Puurunen, J. Appl. Phys. 113, 021301 (2013).

${ }^{9}$ T. Suntola, Appl. Surf. Sci. 100-101, 391 (1996).

${ }^{10}$ T. Suntola, Thin Solid Films 216, 84 (1992).

${ }^{11}$ S. L. Wegener, T. J. Marks, and P. C. Stair, Acc. Chem. Res. 45, 206 (2012).

${ }^{12}$ R. L. Puurunen, J. Appl. Phys. 97, 121301 (2005).

${ }^{13}$ R. L. Puurunen, W. Vandervorst, W. F. A. Besling, O. Richard, H. Bender, T. Conard, C. Zhao, A. Delabie, M. Caymax, S. de Gendt, M. Heyns, M. M. Viitanen, M. de Ridder, H. H. Brongersma, Y. Tamminga, T. Dao, T. de Win, M. Verheijen, M. Kaiser, and M. Tuominen, J. Appl. Phys. 96, 4878 (2004).

${ }^{14}$ D. Longrie, D. Deduytsche, and C. Detavernier, J. Vac. Sci. Technol., A 32, 010802 (2014).

${ }^{15}$ C.-L. Duan, X. Liu, B. Shan, and R. Chen, Rev. Sci. Instrum. 86, 075101 (2015).

${ }^{16}$ E.-L. Lakomaa, Appl. Surf. Sci. 75, 185 (1994).

${ }^{17}$ L. F. Hakim, S. M. George, and A. W. Weimer, Nanotechnology 16, S375S381 (2005).

${ }^{18}$ A. P. Didden, J. Middelkoop, W. F. A. Besling, D. E. Nanu, and R. van de Krol, Rev. Sci. Instrum. 85, 013905 (2014).

${ }^{19}$ A. S. Cavanagh, C. A. Wilson, A. W. Weimer, and S. M. George, Nanotechnology 20, 255602 (2009).

${ }^{20}$ J. W. Elam, M. D. Groner, and S. M. George, Rev. Sci. Instrum. 73, 2981 (2002).

${ }^{21}$ J. Camacho-Bunquin, H. Shou, P. Aich, D. R. Beaulieu, H. Klotzsch, S. Bachman, C. L. Marshall, A. Hock, and P. Stair, Rev. Sci. Instrum. 86, 084103 (2015). 
${ }^{22}$ S. Haukka, A. Kytökivi, E.-L. Lakomaa, U. Lehtovirta, M. Lindblad, V. Lujala, and T. Suntola, Stud. Surf. Sci. Catal. 91, 957 (1995).

${ }^{23}$ G. Ertl, H. Knözinger, F. Schüth, and J. Weitkamp, Handbook of Heterogeneous Catalysis (Wiley-VCH Verlag GmbH \& Co. KGaA, Weinheim, Germany, 2008).

${ }^{24}$ T. W. Weber and R. K. Chakravorti, AIChE J. 20, 228 (1974).

${ }^{25}$ B. S. Lim, A. Rahtu, and R. G. Gordon, Nat. Mater. 2, 749 (2003).

${ }^{26}$ J. A. Klug, M. S. Weimer, J. D. Emery, A. Yanguas-Gil, S. Seifert, C. M. Schleputz, A. B. F. Martinson, J. W. Elam, A. S. Hock, and T. Proslier, Rev. Sci. Instrum. 86, 113901 (2015).

${ }^{27}$ A. C. Dillon, A. W. Ott, J. D. Way, and S. M. George, Surf. Sci. 322, 230 (1995).

${ }^{28}$ E. Langereis, S. B. S. Heil, H. C. M. Knoops, W. Keuning, M. C. M. van de Sanden, and W. M. M. Kessels, J. Phys. D: Appl. Phys. 42, 073001 (2009).

${ }^{29}$ A. Rahtu, T. Alaranta, and M. Ritala, Langmuir 17, 6506 (2001).

${ }^{30}$ A. Koukitu, N. Takahashi, and H. Seki, J. Cryst. Growth 146, 467 (1995).

${ }^{31}$ A. Koukitu, N. Takahashi, Y. Miura, and H. Seki, Jpn. J. Appl. Phys., Part 1 33, L613-L616 (1994).
${ }^{32}$ V. A. Tolmachev, J. Appl. Chem. USSR 55, 1298 (1982), available at http://chemport.cas.org/cgi-bin/sdcgi?APP=ftslink\&action=reflink\&ori gin $=$ aip $\&$ version $=1.0 \&$ coi $=1 \% 3 \mathrm{ACAS} \% 3 \mathrm{~A} 528 \% 3 \mathrm{ADyaL} 38 \mathrm{Xlt}$ Vegtro $\% 2$ 53D\&md5=33d5f4cf8ebc7c0bdf97acd4a7bc12c3.

${ }^{33}$ A. Tarasov, H. Düdder, K. Mette, S. Kühl, K. Kähler, R. Schlögl, M. Muhler, and M. Behrens, Chem. Ing. Tech. 86, 1916 (2014).

${ }^{34}$ S. Simonato, H. Groger, J. Mollmer, R. Staudt, A. Puls, F. Dreisbach, and C. Feldmann, Chem. Commun. 48, 844 (2012).

${ }^{35}$ M. D. Groner, F. H. Fabreguette, J. W. Elam, and S. M. George, Chem. Mater. 16, 639 (2004).

${ }^{36}$ Y.-h. Xie, B. Li, W.-Z. Weng, Y.-P. Zheng, K.-T. Zhu, N.-W. Zhang, C.-J. Huang, and H.-L. Wan, Appl. Catal., A 504, 179 (2015).

${ }^{37}$ B. Li, H. Li, W.-Z. Weng, Q. Zhang, C.-J. Huang, and H.-L. Wan, Fuel 103, $1032(2013)$

${ }^{38}$ F. Rouquerol, J. Rouquerol, K. S. W. Sing, P. L. Llewellyn, and G. Maurin, Adsorption by Powders and Porous Solids: Principles, Methodology and Applications (Elsevier/Academic Press, Amsterdam, 2014).

${ }^{39}$ V. E. Strempel, K. Knemeyer, R. Naumann d'Alnoncourt, M. Driess, and F. Rosowski "Investigating the trimethylaluminium/water ALD process on mesoporous silica by in situ gravimetric monitoring" (unpublished).

${ }^{40}$ Rubotherm GmbH, 2017. 